\title{
Malignant schwannoma of the upper mediastinum originating from the vagus nerve Fumihiro Shoji ${ }^{* 1}$, Riichiroh Maruyama1, Tatsuro Okamoto ${ }^{1}$, Hiroshi Wataya $^{1}$, Kenichi Nishiyama ${ }^{2}$ and Yukito Ichinose ${ }^{1}$
}

\author{
Address: ${ }^{1}$ Department of Thoracic Oncology, Kyushu Cancer Center, 3-1-1, Notame, Minami-ku, Fukuoka 811-1395, Japan and ${ }^{2}$ Department of \\ Pathology, Kyushu Cancer Center, 3-1-1, Notame, Minami-ku, Fukuoka 811-1395, Japan \\ Email: Fumihiro Shoji* - shoji-f@koseikan.jp; Riichiroh Maruyama - rmaruyama@nk-cc.go.jp; Tatsuro Okamoto - tokamoto@nk-cc.go.jp; \\ Hiroshi Wataya - hwataya@nk-cc.go.jp; Kenichi Nishiyama - kennishi@nk-cc.go.jp; Yukito Ichinose - yichinos@nk-cc.go.jp \\ * Corresponding author
}

Published: 06 October 2005

World Journal of Surgical Oncology 2005, 3:65 doi:10.1 186/1477-78/9-3-65

This article is available from: http://www.wjso.com/content/3/l/65

(C) 2005 Shoji et al; licensee BioMed Central Ltd.

This is an Open Access article distributed under the terms of the Creative Commons Attribution License (http://creativecommons.org/licenses/by/2.0), which permits unrestricted use, distribution, and reproduction in any medium, provided the original work is properly cited.
Received: 03 June 2005

Accepted: 06 October 2005

\begin{abstract}
Background: Malignant schwannoma of the upper mediastinum originating from the vagus nerve is extremely rare.

Case presentation: A 46-year-old female was admitted for a left cervical mass which was associated with both hoarseness and Horner's syndrome. Chest computed tomography showed a mass extending from the left upper mediastinum to the left supraclavicular area. A fine needle aspiration cytological examination suggested primary lung cancer stage IIIB large cell carcinoma. After administering induction chemo-radiotherapy, a complete surgical resection was performed. The tumor was found to involve both the left vagus nerve and the left sympathetic nerve. Histological examination of the resected specimen revealed the tumor to be malignant schwannoma.
\end{abstract}

Conclusion: Despite incorrect preoperative diagnosis, the multimodality treatment administered in this case, including induction chemo-radiotherapy and surgery, proved to be effective.

\section{Background}

According to a collected series of 2399 cases of mediastinal tumors reported in the literature [1], 496 cases $(20.7 \%)$ were of neurogenic tumors, and most of them occurred in the posterior mediastinum. Neurogenic tumors can be divided into two groups depending on their origin: those that arise from the nerve sheath and those that arise from nerve cells. The majority of the tumors of nerve sheath origin in adults are either benign schwannomas or neurofibromas, and they usually arise from either an intercostal nerve or a sympathetic nerve.
Intrathoracic schwannoma originating from the vagus nerve, is extremely rare.

\section{Case presentation}

A 46-year-old female with symptoms of hoarseness and Horner's syndrome presented with a left cervical mass that was diagnosed to be undifferentiated carcinoma based on the findings of aspiration cytology (Figure 1). The patient's chest computed tomography (CT) findings showed a mass measuring $5.0 \mathrm{~cm}$ in size spreading from the left upper mediastinum to the left supraclavicular area, which pressed against both the trachea and 


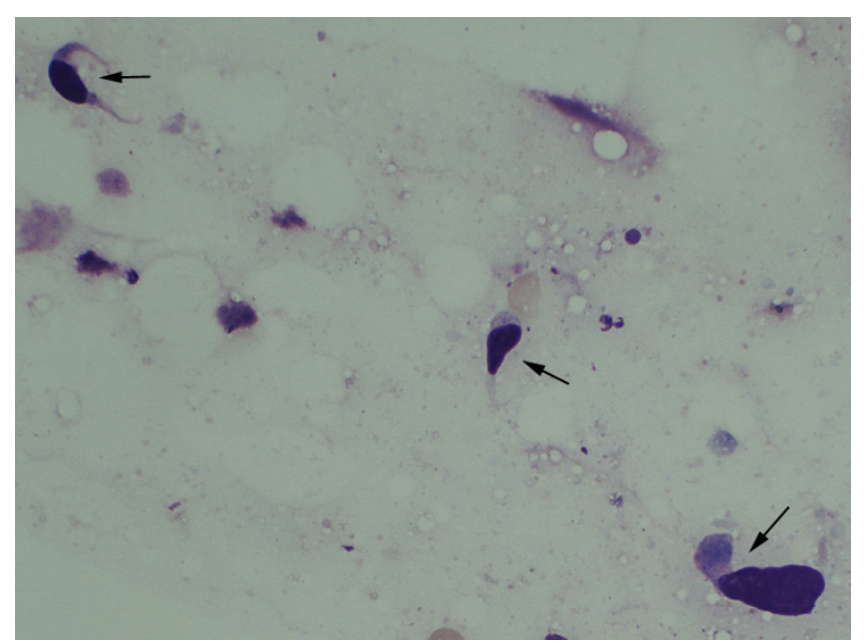

\section{Figure I}

Aspiration cytology of the tumor before treatment showing scattered atypical spindle cells (arrows) (Giemsa staining, high power view $\times 400$ ).

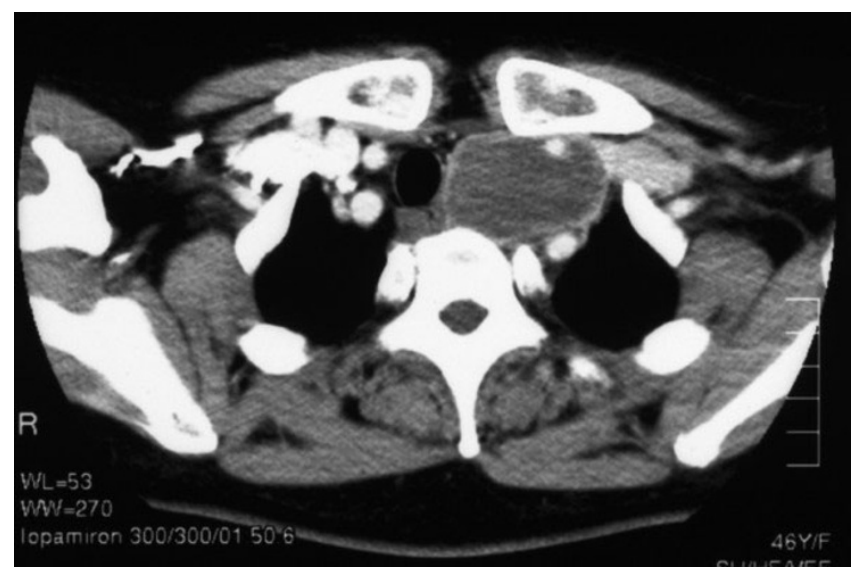

Figure 2

Chest CT showed a mass, measuring $5.0 \mathrm{~cm}$ in size in the upper mediastinum.

esophagus and it seemed to involve the left common carotid artery (Figure 2). Based on these findings, and cytology findings a clinical diagnosis of stage IIIB (T4N3M0) non-small cell lung cancer (NSCLC) originating from the apex of the left lung involving both the mediastinum and the supraclavicular lymph nodes was made [2]. The patient received concurrent chemo-radiotherapy (cisplatin $80 \mathrm{mg} / \mathrm{m}^{2}$ for days 8 and $36+$ UFT $400 \mathrm{mg} / \mathrm{m}^{2}$, both on days 1-14 and on days 29-42 plus radiotherapy,
2 Gy/day on days 1-20 for a total of $40 \mathrm{~Gy}$ ) [3]. After this treatment regimen, the tumor size decreased by $35.0 \%$. Thereafter, the patient underwent a surgical resection though a median sternotomy with a combined resection of the left clavicle. During the operation, an encapsulated tumor was detected in the mediastinum. Although the tumor was easily ablated from the left common carotid artery, it involved both the left vagus and the sympathetic nerves. As a result, both nerves had to be sacrificed in order to achieve a complete resection of the tumor. Grossly, the tumor was in continuity of the vagus nerve was whitish in color and oval shaped measuring $5 \times 3 \mathrm{~cm}$ in diameter (Figure 3). Both cytological and histological examinations revealed 1) Continuity between the vagus nerve and tumor was seen, while the no continuity between the tumor and the sympathetic nerve was found. 2) The findings of aspiration cytology of the tumor diagnosing it to be undifferentiated carcinoma before the treatment included an atypical spindle cell. (Figure 1). 3) The predominantly tumor consisted of necrotic tissue and a few viable atypical spindle cells (Figure $4 \mathrm{~A}$ ) which were positive for S-100 protein (Figure 4B). As a result, the tumor was considered to arise from the left vagus nerve while invading the left sympathetic ganglion, and was therefore diagnosed it to be a malignant schwannoma. At present, the patient has survived for about 2 years since operation without any recurrence.

\section{Discussion}

Tumors of vagus nerve origin are observed in about $2 \%$ of all neurogenic tumors of the mediastinum [4], however, no instace of malignant schwannoma was reported in this review. To our knowledge, only a few such cases have been previously reported [5-7]. As a result, malignant schwannoma originating from the vagus nerve is therefore considered to be extremely rare.

Malignant peripheral nerve sheath tumors (MPNST) including malignant schwannoma are the malignant variants of schwannomas and neurofibromas. Although the 5-year survival rates have been reported to be up to 75 $\%$ in MPNST's patients, MPNST often advance locally and can also occasionally metastasize to the lung or other organs [8]. Therefore, in addition to a complete surgical resection, adjuvant therapy is usually advocated. However, in an adjuvant setting, the efficacy of chemotherapy or radiotherapy appears to provide little additional benefit $[9,10]$. We previously reported concurrent chemo-radiotherapy with UFT plus cisplatin as an induction treatment followed by a surgical resection for patients with marginally resectable stage IIIB NSCLC to be both a feasible and promising treatment [3]. Since we preoperatively considered the disease to be marginally resectable stage IIIB NSCLC, we performed concurrent induction chemo-radiotherapy followed by surgery. As a result, this 


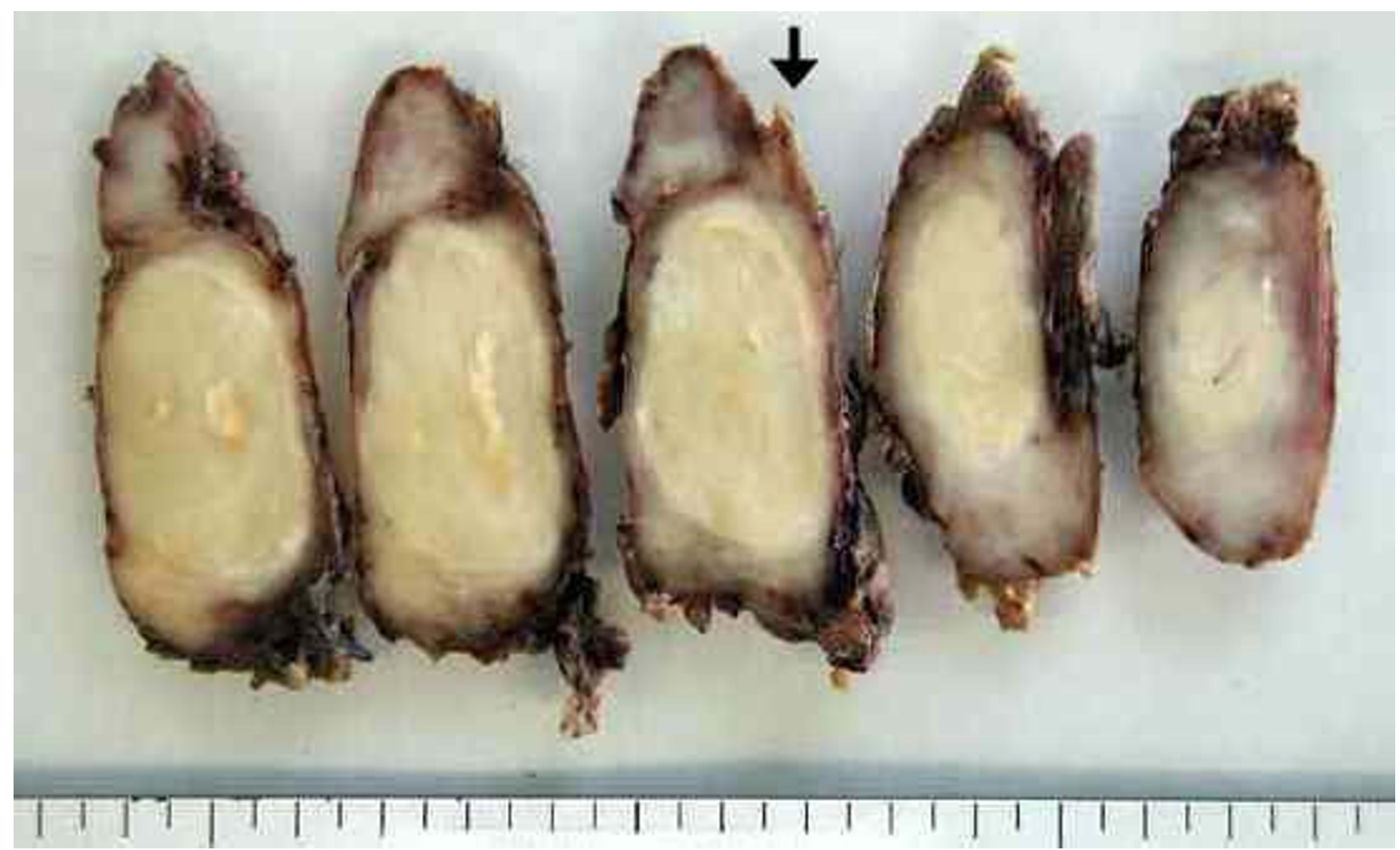

\section{Figure 3}

Macroscopic findings of the tumor. The tumor showing the continuity of the vagus nerve (arrow head) was whitish in color and oval shaped while measuring $5 \times 3 \mathrm{~cm}$ in diameter.
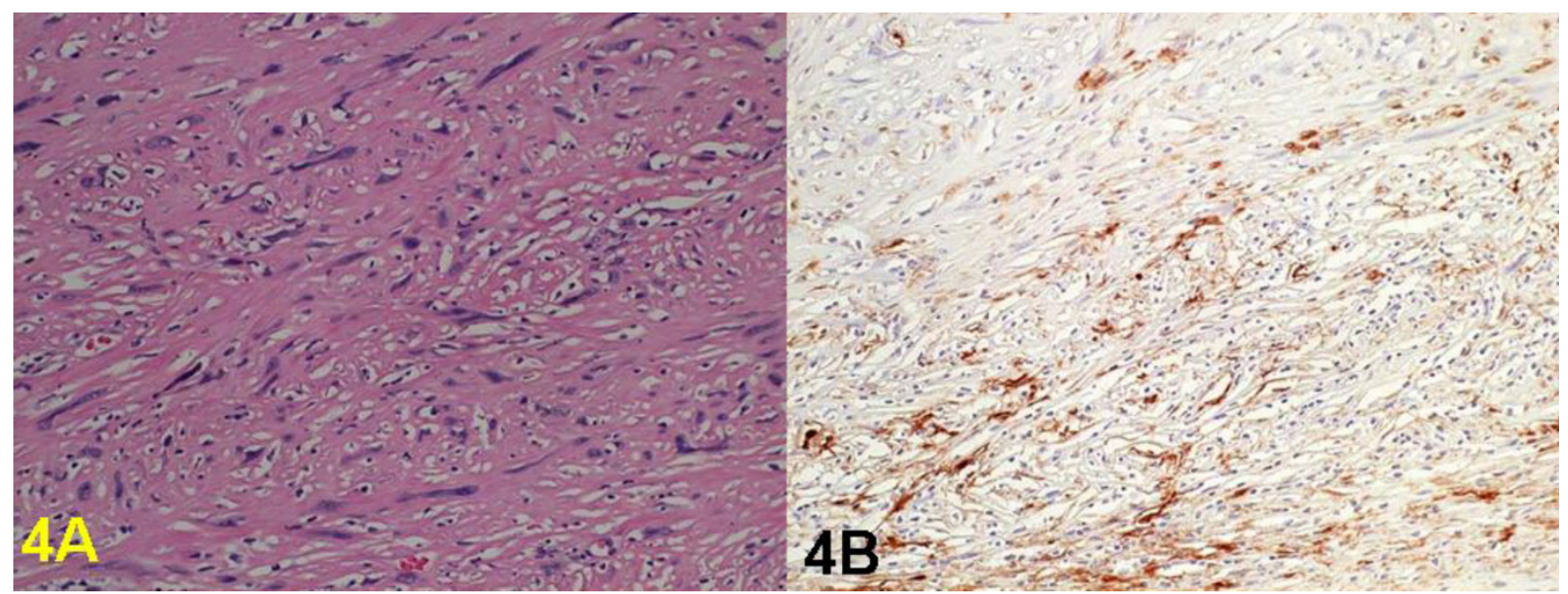

\section{Figure 4}

Histological findings of the tumor. 4A) The tumor was found to consist of a few of viable atypical spindle cells with hyperchromatic nuclei (Hematoxilin-eosin staining $\times 200$ ) 4B). Tumor cells were positive for S- 100 protein (immunohistochemical staining, original magnification: $\times 200)$. 
multimodality treatment proved to be effective and the patient is now doing well without any recurrence.

We initially misdiagnosed this patient's disease to be nonsmall cell lung cancer. The reason for this was partly due to the cytological findings which indicated undifferentiated carcinoma. In general, an exact diagnosis cannot always be made based on the findings of aspiration cytology alone. The second reason for a misdiagnosis in this case was due to the patient's symptoms which included hoarseness and Horner's syndrome. Apical lung cancer involving both the vagus and the sympathetic nerve is occasionally observed. However, to the best of our knowledge, the present case is considered to be the first case demonstrating malignant schwannoma of the vagus nerve involving the sympathetic nerve.

\section{Conclusion}

Malignant schwannoma of the upper mediastinum arising from the vagus nerve is rare. The multimodality treatment administered in this case, including induction chemo-radiotherapy and surgery, proved to be effective.

\section{Competing interests}

The author(s) declare that they have no competing interests.

\section{Authors' contributions}

FS: conceived of the study, participated in its design and coordination and drafted the manuscript.

RM and TO: carried out the literature search and helped in drafting the manuscript.

HW: participated in the design of the study and helped in drafting the manuscript.

KN: performed histological examination and provided photographs.

YI: shaped the idea for the study, coordinated the study and edited the manuscript.

All authors read and approved the final manuscript.

\section{Acknowledgements}

We thank Mr. Brian Quinn for critical comments on the manuscript.

Written consent was obtained from the patient for the publication of this case.

\section{References}

I. Davis RD, Oldham HN, Sabiston DC: Primary cysts and neoplasms of the mediastinum: recent changes in clinical presentation, methods of diagnosis, management, and results. Ann Thorac Surg 1987, 44:229-237.
2. Travis WD, Colby TV, Corrin B: World Health Organization International Histological Classification of Tumors. Histological typing of Lung and Pleural Tumors, 3 rd ed. Berlin: Springer Verlag; 1999.

3. Ichinose $\mathrm{Y}$, Fukuyama $\mathrm{Y}$, Asoh H, Ushijima C, Okamoto T, Ikeda J, Okamoto J, Sakai M: Induction chemoradiotherapy and surgical resection for selected stage IIIB non-small cell lung cancer. Ann Thorac Surg 2003, 76:1810-1814.

4. Sugio K, Inoue T, Inoue K, Tateishi M, Ishida T, Sugimachi K: Neurogenic tumors of the mediastinum originated from the vagus nerve. Eur J Surg Oncol 1995, 21:214-216.

5. Maebeya S, Miyoshi S, Fujiwara K, Sekii H, Suzuka T, Yoshimasu T, Naito Y, Nishino E: Malignant schwannoma of the intrathoracic vagus nerve:report of a case. Surg Today 1993, 23:1078-1080.

6. Yano T, Hara N, Ichinose Y, Maeda K, Yokoyama H, Ohta M: An intrathoracic vagus nerve schwannoma invading the trachea. Surg Today 1993, 23:1113-11115.

7. Suzuki H, Yamaguchi Y, Kimura H, Shiba M, Baba M, Hiroshima K: Malignant mediastinal schwannoma associated with von Recklinghausen's disease. J Jpn Assn Thorac Surg 1996, 44:864-868.

8. Marchevsky AM: Mediastinal tumors of peripheral nerve system origin. Semin Diagn Pathol 1999, 16:65-78.

9. Lodding P, Kindblom LG, Angervall L: Epithelioid malignant schwannoma. A study of 14 cases. Virchows Arch 1986, 409 A:433-45I.

10. Fukai I, Masaoka A, Yamakawa Y, Niwa H, Eimoto T: Mediastinal malignant epithelioid schwannoma. Chest 1995, 108:574-575.
Publish with Biomed Central and every scientist can read your work free of charge

"BioMed Central will be the most significant development for disseminating the results of biomedical research in our lifetime. "

Sir Paul Nurse, Cancer Research UK

Your research papers will be:

- available free of charge to the entire biomedical community

- peer reviewed and published immediately upon acceptance

- cited in PubMed and archived on PubMed Central

- yours - you keep the copyright

Submit your manuscript here:

http://www.biomedcentral.com/info/publishing_adv.asp
BioMedcentral 